\title{
EFFECT OF STERILIZATION PARAMETERS ON QUALITY OF COMMERCIALLY-PREPARED INSTANT SOUPS
}

\author{
Asnate Kirse-Ozolina ${ }^{1}$, Sandra Muizniece-Brasava ${ }^{1}$, Evalds Raits ${ }^{1,2}$, Zanda Kruma ${ }^{1}$ \\ ${ }^{1}$ Latvia University of Life Sciences and Technologies, Latvia; ${ }^{2}$ Kronis Ltd., Latvia \\ asnate.kirse@1lu.lv, sandra.muizniece@1lu.lv, evalds.raits@gmail.com, zanda.kruma@1lu.lv
}

\begin{abstract}
Ready-made meals have gained attention due to saving additional time, which can be spent with family; even better if they do not contain preservatives. At the moment such combination can be obtained using sterilization. The aim of the research was to evaluate and compare currently used processing parameters and packaging solutions to alternative options in order to improve the quality of two commercially-prepared instant soups. A total of seven sterilization, preparation method and packaging combinations were tested for yellow pea soup and fresh cabbage borsch. Such parameters as water activity, $\mathrm{pH}$, aroma volatiles, colour, density of soups and hardness of vegetable pieces, in addition to sensory evaluation by experts were analysed. The results show that it is possible to shorten sterilization cycle up to two times by replacing glass jars with flexible multilayer doypacks, which would have a potential economic benefit by significantly decreasing energy consumption during production. Correct sterilization parameters can retain more intense colour and higher sum of aroma volatiles in addition to excellent sensory quality of both borsch and pea soup. In order to obtain reduced energy consumption and very good quality for both soups the recommended processing parameters are: cold preparation method, doypack packaging and sterilization at $116^{\circ} \mathrm{C}$ temperature.
\end{abstract}

Keywords: aroma volatiles, packaging, thermal processing, soup, quality evaluation.

\section{Introduction}

Modern lifestyle and the fast pace of living has led to an increased consumption of convenience foods, as consumers choose to spend most of their free time with family than preparing timeconsuming meals from scratch [1-2]. Consumers prefer ready-made (ready-to-eat, ready-to-heat) meals with an adequate shelf life, free from preservatives.

In order to ensure shelf-stable food quality, the chosen thermal processing and packaging solutions play an important role. Shelf-stable liquid or semi-liquid foods undergo processing that produce "commercially sterile" products, therefore, under normal conditions during the food chain these foods will not spoil or be hazardous for the consumer's health [3], as food is rendered free of viable microorganisms and their spores. Therefore, to ensure commercial sterility of low acid canned food ( $\mathrm{pH}>4.6, a_{w}>0.85$ ), a 12-D process (botulinum cook) is required [4]; it is equal to processing at $121^{\circ} \mathrm{C}$ for at least 2.4 minutes. This temperature cannot be reached in the centre of the packaging immediately, therefore optimal heat treatment time and temperature combination is measured using Fvalue $\left(F_{o}\right)$; for reduction of Clostridium botulinum spores, the most heat-resistant pathogen, the minimum F-value is 2.52 [5].

Processing at high temperatures $\left(60\right.$ to $\left.100^{\circ} \mathrm{C}\right)$ for a few hours has been a traditional way to improve food flavour and other sensory properties and extend its shelf life [6], yet, prolonged heating can have a detrimental effect on food quality, including off flavours, bitter and rancid taste, unpleasant colour and texture [7]. Therefore, packaging can have the key role in maintaining food quality during thermal processing, as packaging materials have different heat transfer coefficients and the same processing conditions can result in undercooked or overcooked food [8].

Traditionally, glass jar and metal containers have been used to package shelf-stable foods, yet, nowadays, processing in flexible packaging has become one of the leading processing technologies that ensures long-term storage of products at room temperature, including packaging solutions for military purposes [9]. In addition, flexible films provide faster heat transfer to the product compared to glass and metal, thus reducing energy consumption during the technological process [10-11].

Soup is a substantial part of the daily diet for countries in the Northern hemisphere, and at the moment there are several types of commercially-prepared instant soups in the market. The study was conducted to compare whether currently used processing parameters and packaging solutions result in commercially-prepared instant soups of adequate quality or an alternative should be introduced. 


\section{Materials and methods}

Experimental design. Pilot scale sterilisation and determination of product physical, chemical and sensory properties study was conducted at laboratories of the Faculty of Food Technology, Latvia University of Life Sciences and Technologies, whereas production scale sterilization was carried out at the facilities of the food manufacturer Kronis Ltd.

Soup preparation. Two instant soup types were studied in this research: yellow pea soup (yellow peas $27 \%$, potato $20 \%$, pearl barley $8 \%$, carrot $7 \%$, onion $6 \%$, canola oil $5 \%$, salt $1.8 \%$, sodium glutamate $0.8 \%$, wheat flour $0.7 \%$, dried dill $0.025 \%$, dried parsley $0.025 \%$, water $30 \%$ ) and fresh cabbage borsch (beet $45 \%$, fresh cabbage $10.8 \%$, onion $8 \%$, carrot $8 \%$, potato $6.8 \%$, tomato paste $6.4 \%$, canola oil $4 \%$, salt $1.8 \%$, wheat flour $0.9 \%$, sugar $0.9 \%$, citric acid $0.9 \%$, sodium glutamate $0.7 \%$, black pepper $0.045 \%$, water $14.4 \%$ ). All vegetables were cut into $5 \times 5 \mathrm{~mm}$ pieces; carrot and onion were cooked together with oil and seasonings for $5 \mathrm{~min}$, the rest of dry ingredients and water were added to form soup concentrate. Soups were prepared using two methods. The cold method consisted of mixing previously cooked ingredients with dry peas and barley / fresh cut beet and filling soup concentrate in appropriate packaging; the soup concentrate temperature was $20 \pm 2{ }^{\circ} \mathrm{C}$. Whereas, the hot preparation method consisted of soaking peas and barley separately for 12 hours at $20 \pm 2{ }^{\circ} \mathrm{C}$ temperature, and cooking all mixed ingredients for additional $5 \mathrm{~min}$ before filling, temperature of the soup concentrate was $70 \pm 2{ }^{\circ} \mathrm{C}$.

Soups were filled in traditional glass jars (III-82-500, $500 \mathrm{ml}$ ) and doypacks (PET/ALU/PA/CPP, $134 \mu \mathrm{m}, 240 \times 140 \mathrm{~mm}$, IMMER Ukrplastic Ltd.), volume of soups per package $-500 \mathrm{ml}$. Each package was hermetically closed and subjected to sterilisation.

Sterilisation treatments. Sterilisation was carried out in 2 stages (Table 1). Preliminary study was conducted at the Faculty of Food Technology using a pilot autoclave HST 50/100 (ZIRBUS Technology GmbH, Germany). The experiment was then upscaled and conducted in the WSA 113 autoclave (SPOMASZ Pleszew S.A., Poland) at Kronis Ltd. production facilities.

Table 1

\section{Processing parameters of commercially-prepared instant soups}

\begin{tabular}{|c|c|c|c|c|c|c|}
\hline \multirow{2}{*}{$\begin{array}{c}\text { Experiment } \\
\text { stage }\end{array}$} & \multirow{2}{*}{$\begin{array}{c}\text { Sample } \\
\text { codes }\end{array}$} & \multirow{2}{*}{$\begin{array}{c}\text { Preparation } \\
\text { method }\end{array}$} & \multirow{2}{*}{ Packaging } & \multirow{2}{*}{$\begin{array}{c}\text { Thermal treatment } \\
\text { temperature, }{ }^{\circ} \mathrm{C}\end{array}$} & \multicolumn{2}{|c|}{ Holding time, min } \\
\hline & & & & & Borsch & Pea soup \\
\hline \multirow{4}{*}{ Stage I } & $\mathrm{A}$ & Hot & \multirow{2}{*}{ Glass jar } & \multirow{4}{*}{116} & $62 \pm 1$ & $65 \pm 1$ \\
\hline & $\mathrm{B}$ & Cold & & & $75 \pm 1$ & $72 \pm 1$ \\
\hline & $\mathrm{C}$ & Hot & \multirow{2}{*}{ Doypack } & & $37 \pm 1$ & $38 \pm 1$ \\
\hline & $\mathrm{D}$ & Cold & & & $45 \pm 1$ & $27 \pm 1$ \\
\hline \multirow{4}{*}{ Stage II } & D & Cold & \multirow{4}{*}{ Doypack } & 116 & $45 \pm 1$ & $27 \pm 1$ \\
\hline & $\mathrm{E}$ & Cold & & 111 & $78 \pm 1$ & $70 \pm 1$ \\
\hline & $\mathrm{F}$ & Cold & & 121 & $40 \pm 1$ & $21 \pm 1$ \\
\hline & G & Cold & & 131 & $23 \pm 1$ & $22 \pm 1$ \\
\hline
\end{tabular}

During the first stage, four soup samples were sterilised in order to assess the effect of the preparation method and packaging on the quality of commercially-prepared instant soups. The second stage of the experiment was carried out to evaluate the effect of the sterilisation temperature on the quality of soups by comparing the sample with the highest quality from the first stage and three additional samples. $F_{0}$ value of each soup sample was $3.3 \pm 0.5$.

Quality analysis. Each package of instant soups was puréed using a hand-held blender (Braun MQ 3025 , Braun $\mathrm{GmbH}$, Germany) to analyse water activity, colour, $\mathrm{pH}$ and aroma volatiles. Water activity $\left(a_{w}\right)$ was measured using LabSwift- $a_{w}$ water activity meter (Novasina AG, Switzerland) in triplicate.

For $\mathrm{pH}$ value determination, each puréed instant soup sample as filled in a $50 \mathrm{ml}$ glass beaker and $\mathrm{pH}$ was measured at ambient temperature using Jenway $3520 \mathrm{pH}$ meter (Barloworld Scientific Ltd, UK) in triplicate.

Volatiles from soups were extracted using solid phase microextraction (SPME). $5 \mathrm{~g}$ of sample were weighed in a $20 \mathrm{ml}$ headspace vial and capped with a septum. A Carboxen/Polydimethylsiloxane (Car/PDMS) fiber (Supelco Inc., Bellefonte, PA, USA) was used for headspace SPME sampling with 
the following parameters: incubation time $15 \mathrm{~min}$, extraction duration $15 \mathrm{~min}$, incubation and extraction temperature $60 \pm 1{ }^{\circ} \mathrm{C}$, desorption $15 \mathrm{~min}$ at $250^{\circ} \mathrm{C}$. For the analysis of SPME extracts, a Perkin Elmer Clarus 500 GC/MS and an Elite-Wax ETR $(60 \mathrm{~m} \times 0.25 \mathrm{~mm}$ i.d.; DF $0.25 \mu \mathrm{m})$ was used. The working conditions were as follows: injector $250^{\circ} \mathrm{C}$; transfer line to MSD $260{ }^{\circ} \mathrm{C}$; initial oven temperature $40^{\circ} \mathrm{C}$, hold $7 \mathrm{~min}$, ramped up from 40 to $160{ }^{\circ} \mathrm{C}$ at $6^{\circ} \mathrm{C} \mathrm{min}{ }^{-1}$, hold $10 \mathrm{~min}$, and from 160 to $210^{\circ} \mathrm{C}$ at $10^{\circ} \mathrm{C} \mathrm{min}^{-1}$, hold $15 \mathrm{~min}$; carrier gas (He) $1 \mathrm{ml} \cdot \mathrm{min}^{-1}$; split ratio $2: 1$; ionization $\mathrm{EI}+$; acquisition parameters in full scan mode - scanned $\mathrm{m} / \mathrm{z}$ 40-300. Compounds were identified by comparison of their mass spectra with mass spectral libraries (Nist98), and by calculation of linear retention indexes and comparison with literature data. All analyses were performed in triplicate. As a quantitative measure, the share in the total GC peak area (PAU) for each compound is given.

Colour components of instant soups in CIE $L * a * b *$ colour system were determined instrumentally with a handheld colour instrument Colour Tec PCM/PSM (Accuracy Microsensors Inc., USA). Pureed soup was placed in a Petri dish $(\varnothing 50 \mathrm{~mm})$ on a white paper and colour was measured in tenfold repetition at different spots through the lid. The influence of the sterilization parameters on soup colour was assessed as the total colour difference $\left(\Delta E^{*}\right)$, it was calculated according to the following equation [12]:

$$
E^{*}=\sqrt{\left(L^{*}-L_{0}^{*}\right)^{2}+\left(a^{*}-a_{0}^{*}\right)^{2}+\left(b^{*}-b_{0}^{*}\right)^{2}},
$$

where $\Delta E^{*}-$ total colour difference;

$L^{*}, a^{*}$ and $b^{*}-$ colour values of tested soups;

$L_{0}{ }^{*}{ }^{2} a_{0}{ }^{*}$ and $b_{0}{ }^{*}$ - colour values of soup samples already on the market.

The differences in perceivable colour $\left(\Delta E^{*}\right)$ were classified as not noticeable (0-0.5), slightly noticeable (0.5-1.5), noticeable (1.5-3.0), well visible (3.0-6.0), and great (6.0-12.0) [13; 14]. In addition, $\Delta E^{*}$ value of 2.8 was considered as the colour difference threshold for untrained panellists and consumers [15].

Texture of instant soups was measured instrumentally using TA.XTplus Texture Analyser (Stable Micro Systems, UK) with ten-fold repetition and the data were processed with Texture Exponent 32. Testing of the whole sample was carried out by opening the jar or doypack and positioning it under the probe. Density of the sample in packaging (expressed as hardness in $\mathrm{N}$ ) was measured using the following parameters: multiple puncture probe, pre-test speed $10 \mathrm{~mm} \cdot \mathrm{s}^{-1}$, test speed $2 \mathrm{~mm} \cdot \mathrm{s}^{-1}$, target mode - distance $70 \mathrm{~mm}$, trigger force $0.29 \mathrm{~N}$. In order to test vegetable and grain pieces, soup was mixed with boiling water $(1: 1)$ and left to sit for $3 \mathrm{~min}$. Then pieces were separated from water by straining and placed on a Petri dish. Necessary bite force of product pieces (expressed as hardness in $\mathrm{N}$ ) was measured using the following compression test parameters: stainless cylinder $\varnothing 2 \mathrm{~mm}$, pre-test speed $1.5 \mathrm{~mm} \cdot \mathrm{s}^{-1}$, test speed $0.5 \mathrm{~mm} \cdot \mathrm{s}^{-1}$, target mode - distance $2 \mathrm{~mm}$, trigger force $0.049 \mathrm{~N}$.

Sensory evaluation of instant soups was conducted by five experts (60\% women and $40 \%$ men, average age 34 years). Evaluation forms were prepared prior to the sensory evaluation, based on the experts' shared understanding about the characteristics of the product (ISO 8586:2012). Sensory quality of instant soups was evaluated using descriptive methods (Table 2) and the assessment of such sensory parameters as the overall appearance, flavour, hardness of pieces, colour of broth and colour of beet, pea and potato pieces was completed by consensus of all selected experts. Each sensory parameter was assessed within a scale of 3 (very good quality) to 1 (unsatisfactory quality) and given a quality number $(Q N)$. The quality number was calculated by the following equation [16]:

$$
Q N=\frac{O A+F+H+C+C P}{5},
$$

where $O A$ - overall appearance;

$F$ - flavour;

$H$ - hardness of pieces;

$C$ - colour of broth;

$C P-$ colour of beet, pea and potato pieces. 
Sensory quality of instant soups was classified as follows: 3.00-2.70 very good quality, 2.69-2.20 average quality (noticeable deviations), 2.19-1.00 unsatisfactory quality (significant deviations).

In order to test sensory quality, each soup was mixed with boiling water (1:1) in a 1 litre pot and cooked for $3 \mathrm{~min}$ (as per instructions on soup label). Each expert received an evaluation form, $100 \mathrm{ml}$ glass beakers with coded samples, unflavoured crackers and warm tea without sugar (to clear the palate between samples). Additionally, $50 \mathrm{ml}$ glass beakers were filled only with soup broth, whereas soup solids were placed on a Petri dish $(\varnothing 90 \mathrm{~mm})$ to give a better view on the colour of separate soup fractions.

Table 2

Sensory parameters of commercially-prepared instant soups

\begin{tabular}{|c|c|c|c|}
\hline $\begin{array}{c}\text { Sensory } \\
\text { parameters }\end{array}$ & Sensory characteristics & $\begin{array}{c}\text { Quality } \\
\text { number }(Q N)\end{array}$ & $\begin{array}{l}\text { Quality of } \\
\text { soup }\end{array}$ \\
\hline \multirow{3}{*}{$\begin{array}{c}\text { Overall } \\
\text { appearance }\end{array}$} & $\begin{array}{c}\text { colour appropriate for soup type, broth and } \\
\text { pieces in similar ratio }(1: 1) \text {, easy to notice } \\
\text { separate vegetables }\end{array}$ & 3 & very good \\
\hline & $\begin{array}{l}\text { soup is too thick when stirred, easy to notice } \\
\text { separate vegetables, colour is darker or lighter }\end{array}$ & 2 & average \\
\hline & $\begin{array}{c}\text { inadequate to soup type, non-appetizing } \\
\text { colour, pieces have dissolved (overcooked), } \\
\text { hard to notice separate vegetables }\end{array}$ & 1 & unsatisfactory \\
\hline \multirow{3}{*}{ Flavour } & $\begin{array}{c}\text { pleasant, distinctive and recognizable flavour } \\
\text { of each soup }\end{array}$ & 3 & very good \\
\hline & $\begin{array}{l}\text { characteristic to soup type, broth slightly } \\
\text { watery or too thick }\end{array}$ & 2 & average \\
\hline & $\begin{array}{c}\text { inadequate aroma, unpleasant taste and } \\
\text { aftertaste }\end{array}$ & 1 & unsatisfactory \\
\hline \multirow{3}{*}{$\begin{array}{c}\text { Hardness of } \\
\text { pieces (peas, } \\
\text { barley and } \\
\text { beet) }\end{array}$} & $\begin{array}{l}\text { good consistency, easy to chew, however, } \\
\text { pieces are perceptible }\end{array}$ & 3 & very good \\
\hline & too tender or hard & 2 & average \\
\hline & $\begin{array}{l}\text { breaks apart easily in mouth (over-tender), } \\
\text { overcooked, pieces have dissolved }\end{array}$ & 1 & unsatisfactory \\
\hline \multirow{3}{*}{$\begin{array}{l}\text { Colour of } \\
\text { broth }\end{array}$} & $\begin{array}{l}\text { characteristic to soup type, beet red (for } \\
\text { borsch) }\end{array}$ & 3 & very good \\
\hline & $\begin{array}{l}\text { lighter or darker colour (for pea soup), light } \\
\text { red or orange (for borsch) }\end{array}$ & 2 & average \\
\hline & dark, brown, non-appetizing & 1 & unsatisfactory \\
\hline \multirow{3}{*}{$\begin{array}{c}\text { Colour of } \\
\text { beet, pea and } \\
\text { potato pieces }\end{array}$} & $\begin{array}{l}\text { characteristic to soup type, beets are red, peas } \\
\text { and potatoes are yellow }\end{array}$ & 3 & very good \\
\hline & $\begin{array}{c}\text { beets are light red or orange, peas and potatoes } \\
\text { are lighter or darker, off yellow }\end{array}$ & 2 & average \\
\hline & dark, brown, non-appetizing & 1 & unsatisfactory \\
\hline
\end{tabular}

Statistical analysis. Data processing was performed with mathematical and statistical software $R$ 3.0.2 and MS Office Excel v16. The results were given as the mean or the mean $\pm \mathrm{SD}$. The differences were compared using one-way ANOVA and Tukey's test. The differences were considered significant at $p<0.05$.

\section{Results and discussion}

Quality changes depending on preparation method and packaging. Effect of sterilization parameters on the quality of commercially-prepared instant soups was evaluated in 2 stages. Stage I of the experiments was conducted to evaluate the sterilisation effect on fresh cabbage borsch and yellow pea soup, based on the chosen preparation method (hot or cold) and packaging. A total of four samples per each soup type were studied (Table 1). 
The results show that the applied preparation method (hot or cold) and packaging materials had an insignificant effect on $\mathrm{pH}$ of both borsch (4.621 \pm 0.031$)$ and pea soup (5.702 \pm 0.115$)$; water activity was also unaffected for both soups $(0.973 \pm 0.001$ in borsch, $0.981 \pm 0.001$ in pea soup) $(p>0.05)$.

With regards to colour of commercially-prepared instant soups, significant differences among colour parameters were found for borsch and pea soup (Table 3). Soup samples A represent soups currently on the market and were therefore regarded as control samples to calculate the total colour difference $(\Delta E$ value). The results of instrumentally determined colour components showed that borsch samples in doypack (C, D) had a more intense red colour (higher $a$ value), less intense yellow hue $(b$ value) and a slightly darker tone $(L$ value $)(p<0.05)$. These samples had a noticeable change in colour (1.5-3.0) as found by [14], yet, the colour was retained better.

Table 3

Colour of soups using different preparation methods and packaging materials

\begin{tabular}{|c|c|c|c|c|c|}
\hline \multirow{2}{*}{ Soup type } & \multirow{2}{*}{ Sample } & \multicolumn{4}{|c|}{ Colour parameters } \\
\cline { 2 - 6 } & & $\boldsymbol{L}$ & $\boldsymbol{a}$ & $\boldsymbol{b}$ & $\boldsymbol{\Delta}$ \\
\hline \multirow{3}{*}{ Borsch } & $\mathrm{A}$ & $33.49 \pm 0.08 \mathrm{a}$ & $19.26 \pm 0.10 \mathrm{a}$ & $31.59 \pm 0.21 \mathrm{a}$ & - \\
\cline { 2 - 6 } & $\mathrm{B}$ & $33.65 \pm 0.53 \mathrm{a}$ & $18.07 \pm 0.39 \mathrm{~b}$ & $31.23 \pm 0.95 \mathrm{a}$ & 1.26 \\
\cline { 2 - 6 } & $\mathrm{C}$ & $32.87 \pm 0.10 \mathrm{~b}$ & $19.78 \pm 0.10 \mathrm{~b}$ & $29.51 \pm 0.30 \mathrm{~b}$ & 2.23 \\
\cline { 2 - 6 } & $\mathrm{D}$ & $32.55 \pm 0.12 \mathrm{~b}$ & $19.83 \pm 0.16 \mathrm{~b}$ & $29.11 \pm 0.41 \mathrm{~b}$ & 2.75 \\
\hline \multirow{3}{*}{ Pea soup } & $\mathrm{A}$ & $69.99 \pm 0.59 \mathrm{a}$ & $-1.48 \pm 0.45 \mathrm{a}$ & $26.32 \pm 1.13 \mathrm{a}$ & - \\
\cline { 2 - 6 } & $\mathrm{B}$ & $65.04 \pm 0.68 \mathrm{~b}$ & $-0.65 \pm 0.39 \mathrm{~b}$ & $25.49 \pm 1.22 \mathrm{~b}$ & 5.08 \\
\cline { 2 - 6 } & $\mathrm{C}$ & $69.96 \pm 0.29 \mathrm{a}$ & $-1.17 \pm 0.17 \mathrm{a}$ & $26.25 \pm 0.47 \mathrm{a}$ & 0.31 \\
\cline { 2 - 6 } & $\mathrm{D}$ & $70.94 \pm 0.55 \mathrm{a}$ & $-1.14 \pm 0.31 \mathrm{a}$ & $26.85 \pm 0.59 \mathrm{a}$ & 1.15 \\
\hline
\end{tabular}

Values within the same column of the same soup type sharing the same letter are not significantly different $(p>0.05)$.

*compared to sample A (control - commercial soup)

Contrary to the results of borsch, significant differences in all colour components were found for pea soup in a glass jar, prepared using the cold method (Table 3). Sample B was significantly darker, had a less green and yellow hue $(p<0.05)$ and well visible changes in colour $(3.0<\Delta E<6.0)$ as described by [14]. Based on the initial product temperature and heat transfer of glass, sample B was processed for a longer time in order to achieve $F_{0}$ value of $3.3 \pm 0.5$, which negatively affected its colour. Faster heat transfer of flexible packaging is characterised by sterilisation with minimal overcooking and a higher retention of heat labile compounds, including colour [17].

The force necessary to puncture soup samples in packaging characterises the density of the whole sample and indicates the difficulty for consumers to remove the sample from the packaging (Table 4). Both cold and hot preparation method for borsch in glass jars produced a significantly denser sample $(p<0.05)$, therefore, additional utensils (such as spoon or fork) must be used to remove soup from jars. Samples from doypacks can be easily squeezed out by hands. Density of pea soup samples showed even more pronounced differences, soups in glass jars were approx. 3 times denser than the soups in doypacks $(p<0.05)$; it is impossible to remove pea soup from jars without a spoon or a fork, therefore, interfering with ergonomic functionality of packaging [18]. This is due to partially or fully gelatinized starch from vegetables and wheat flour during prolonged cooking [19].

Based on the necessary bite force of product pieces (Table 4), the results demonstrate that the cold preparation method for borsch in glass jars produces significantly harder beet pieces than other preparation methods and packaging conditions $(p<0.05)$. With regards to pea soup, both pea and barley pieces showed a similar trend, significantly harder samples were found in both packaging materials using the cold preparation method $(p<0.05)$; contrary to under- or overcooking, an al dente version of vegetables is desirable.

The results of aroma volatile evaluation showed that borsch had a more diverse aroma volatile profile compared to pea soup, including approx. two times higher sum of peak areas (Fig. 1.) Sample A (glass jar, hot preparation method) of both type soups contained a higher sum of volatile compounds; it was comparable for borsch sample D $(\mathrm{p}>0.05)$. Volatile compounds found in the highest concentration in all borsch samples were ethyl acetate, caryophyllene, dimethyl trisulfide and 
decanoic acid ethyl ester, which form fruity and sweet, woody and spicy, cooked onion and savoury, and waxy and oily odours [20], respectively. Both borsch samples in glass jars had a significant amount of benzaldehyde $\left(3.345 \mathrm{PAU} \times 10^{6}\right)$, which gives a burnt sugar odour.

Table 4

Hardness of soup fractions using different preparation methods and packaging materials, $\mathbf{N}$

\begin{tabular}{|c|c|c|c|c|c|}
\hline \multirow{2}{*}{$\begin{array}{c}\text { Soup } \\
\text { sample }\end{array}$} & \multicolumn{2}{|c|}{ Borsch } & \multicolumn{3}{c|}{ Pea soup } \\
\cline { 2 - 6 } & whole soup & beet pieces & whole soup & pea pieces & barley pieces \\
\hline A & $6.25 \pm 0.46 \mathrm{a}$ & $0.63 \pm 0.13 \mathrm{a}$ & $22.97 \pm 0.83 \mathrm{a}$ & $0.19 \pm 0.03 \mathrm{a}$ & $0.62 \pm 0.09 \mathrm{a}$ \\
\hline $\mathrm{B}$ & $4.71 \pm 0.56 \mathrm{~b}$ & $1.23 \pm 0.18 \mathrm{~b}$ & $37.04 \pm 0.98 \mathrm{~b}$ & $0.38 \pm 0.11 \mathrm{~b}$ & $0.80 \pm 0.10 \mathrm{~b}$ \\
\hline C & $3.93 \pm 0.16 \mathrm{c}$ & $0.83 \pm 0.18 \mathrm{a}$ & $7.71 \pm 0.15 \mathrm{c}$ & $0.23 \pm 0.07 \mathrm{a}$ & $0.38 \pm 0.13 \mathrm{c}$ \\
\hline $\mathrm{D}$ & $3.52 \pm 0.20 \mathrm{c}$ & $0.82 \pm 0.14 \mathrm{a}$ & $13.37 \pm 0.78 \mathrm{~d}$ & $0.53 \pm 0.10 \mathrm{c}$ & $1.19 \pm 0.10 \mathrm{~d}$ \\
\hline
\end{tabular}

Values within the same column sharing the same letter are not significantly different $(p>0.05)$.

Similarly, in all pea soup samples dominating volatile compounds were ethyl acetate, ethyl alcohol, dipropyl disulphide, which form fruity and sweet, floral, and alliaceous (garlic, onion) odours, respectively. Sample A had a significant amount of allyl isothiocyanate $\left(1.987 \mathrm{PAU} \times 10^{6}\right)$, forming a strong and pungent odour; it was found in $50 \%$ lower amounts in samples B and D (cold preparation method).

Sensory parameters are equally important, as based on negative sensory experiences consumers often forgo purchases in future [1;21]. According to the defined sensory parameters for commercially prepared instant soups (Table 5), the opinion of the experts is summarised in the table. These results suggest that the quality of borsch sample A (glass jar, hot preparation method, representing soups currently on the market) was average. The application of cold preparation and different packaging material can improve the quality of fresh cabbage borsch. Beet pieces of soup sample A had an orange hue and were too soft when chewed (also shown by texture analysis, Table 4), the broth was light red and too thick when stirred. Samples B and C were off colour, regarding both the colour of broth and beet pieces, while still maintaining very good quality. Sample D had no quality deviations.

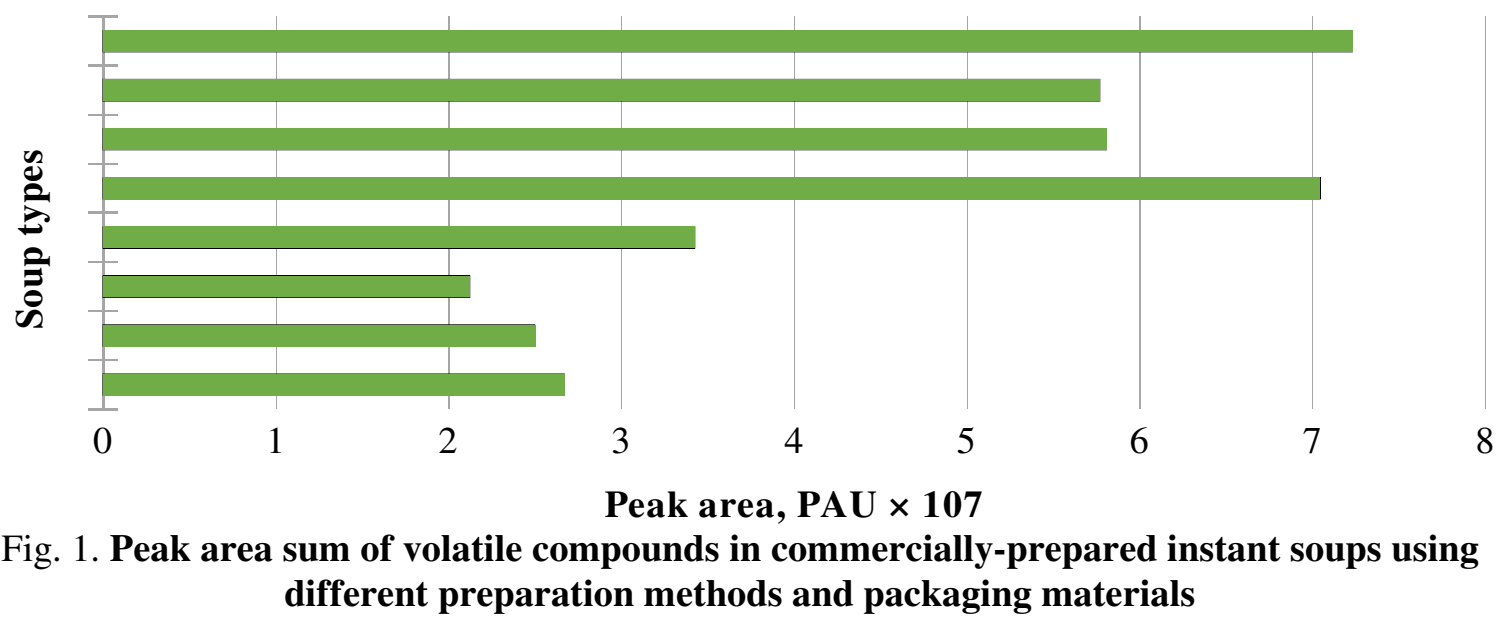

Contrary to borsch, sensory quality of pea soup samples varied considerably (Table 5). Samples A (glass jar, hot preparation method, representing soups currently on the market) and C (doypack, hot preparation method) were of average quality, having overly tender pea pieces and less pronounced flavour. Pea soup in glass jar prepared using the cold method (sample B) was non-appetizing, with little flavour and aroma, the broth was slightly watery, which indicated unsatisfactory quality.

According to the research of Shah et al. (2017), flexible packaging has a considerably thinner profile and a larger surface area in relation to volume, which reduces the processing time by $30-50 \%$, therefore, thermal treatment in flexible packaging improves the sensory properties of the product, in addition to reducing energy consumption [22]. This can be clearly observed by the sensory evaluation data of pea soup.

Based on the results of the first stage of the experiments, the best quality soups were obtained using the cold preparation method and doypack packaging. 


\section{Sensory quality of commercially-prepared instant soups using different preparation methods and packaging materials}

\begin{tabular}{|c|c|c|c|c|}
\hline \multirow{2}{*}{ Soup sample } & \multicolumn{2}{|c|}{ Borsch } & \multicolumn{2}{c|}{ Pea soup } \\
\cline { 2 - 5 } & $Q N$ & Quality & $Q N$ & Quality \\
\hline A & 2.5 & average & 2.3 & average \\
\hline B & 2.7 & very good & 2.0 & unsatisfactory \\
\hline C & 2.7 & very good & 2.3 & average \\
\hline D & 3.0 & very good & 3.0 & very good \\
\hline
\end{tabular}

Quality changes depending on sterilization parameters. Stage II of the experiments was carried out to assess the influence of different sterilisation regimes on the quality of fresh cabbage borsch and yellow pea soup in doypack packaging (Table 1). An insignificant effect of sterilisation temperature on water activity and $\mathrm{pH}$ of both soups was found. Borsch had a $\mathrm{pH}$ of $4.530 \pm 0.080$, while $\mathrm{pH}$ of pea soup was slightly higher $-5.734 \pm 0.062$, water activity was $0.976 \pm 0.002$ and $0.980 \pm 0.001$, respectively.

Inadequate thermal treatment can cause significant colour changes of products when over processing, as most colour compounds are heat labile [23]. Compared to the commercial borsch (sample A), the least colour changes were found in sample D, which had the sterilisation temperature of $116{ }^{\circ} \mathrm{C}$ (Table 6). Lower and higher processing temperatures gave borsch a significantly higher yellowness and lower redness, thus, showing that betalains were degraded [24]. Processing at $111^{\circ} \mathrm{C}$ and $131{ }^{\circ} \mathrm{C}$ had a similar influence on the total colour difference, exceeding the threshold for great (6.0-12.0) changes in colour. Increased colour degradation has previously been associated with heat processing [23; 25]. Processing at $121{ }^{\circ} \mathrm{C}$ showed the least changes compared to sterilisation at $116^{\circ} \mathrm{C}$.

With regards to the colour of pea soup, the differences were not so profound as for borsch (Table 6). Samples $\mathrm{D}\left(116^{\circ} \mathrm{C}\right)$ and $\mathrm{F}\left(121^{\circ} \mathrm{C}\right)$ had a lower total colour difference, which is characterised as slightly noticeable $(0.5-1.5)$ [14].

Table 6

Colour of soups processed at different sterilisation temperatures

\begin{tabular}{|c|c|c|c|c|c|}
\hline \multirow{2}{*}{$\begin{array}{c}\text { Soup } \\
\text { type }\end{array}$} & \multirow{2}{*}{ Sample } & \multicolumn{4}{|c|}{ Colour parameters } \\
\cline { 2 - 6 } & & $\boldsymbol{L}$ & $\boldsymbol{a}$ & $\boldsymbol{b}$ & $\boldsymbol{E}^{*}$ \\
\hline \multirow{4}{*}{ Borsch } & $\mathrm{D}$ & $32.55 \pm 0.12 \mathrm{a}$ & $19.83 \pm 0.16 \mathrm{a}$ & $29.11 \pm 0.41 \mathrm{a}$ & 2.75 \\
\cline { 2 - 6 } & $\mathrm{E}$ & $37.63 \pm 0.22 \mathrm{~b}$ & $17.79 \pm 0.04 \mathrm{~b}$ & $37.03 \pm 0.25 \mathrm{~b}$ & 7.00 \\
\cline { 2 - 6 } & $\mathrm{F}$ & $35.24 \pm 0.22 \mathrm{c}$ & $17.79 \pm 0.14 \mathrm{~b}$ & $33.96 \pm 0.49 \mathrm{c}$ & 3.29 \\
\cline { 2 - 6 } & $\mathrm{G}$ & $39.21 \pm 0.21 \mathrm{~d}$ & $15.75 \pm 0.13 \mathrm{c}$ & $40.01 \pm 0.26 \mathrm{~d}$ & 10.77 \\
\hline \multirow{3}{*}{$\begin{array}{c}\text { Pea } \\
\text { soup }\end{array}$} & $\mathrm{D}$ & $70.94 \pm 0.55 \mathrm{a}$ & $-1.14 \pm 0.31 \mathrm{a}$ & $26.85 \pm 0.59 \mathrm{a}$ & 1.15 \\
\cline { 2 - 6 } & $\mathrm{E}$ & $69.61 \pm 0.47 \mathrm{~b}$ & $-1.24 \pm 0.50 \mathrm{a}$ & $28.52 \pm 1.00 \mathrm{~b}$ & 2.25 \\
\cline { 2 - 6 } & $\mathrm{F}$ & $69.95 \pm 0.52 \mathrm{~b}$ & $-2.28 \pm 0.66 \mathrm{~b}$ & $27.39 \pm 0.81 \mathrm{c}$ & 1.34 \\
\cline { 2 - 6 } & $\mathrm{G}$ & $65.68 \pm 0.58 \mathrm{c}$ & $-1.36 \pm 0.45 \mathrm{a}$ & $28.68 \pm 0.95 \mathrm{~b}$ & 4.91 \\
\hline
\end{tabular}

Values within the same column of the same soup type sharing the same letter are not significantly different $(p>0.05)$.

*compared to sample A (control - commercial soup)

Several authors have reported the correlation between consumers' acceptability and total colour difference $[15 ; 26] . \Delta E^{*}$ value of 2.8 has been reported as the colour difference threshold for untrained panellists and consumers [15], thus suggesting that processing at $116^{\circ} \mathrm{C}$ is the optimal temperature for borsch and treatment at $131{ }^{\circ} \mathrm{C}$ is the least suitable temperature for pea soup, according to the colour changes after sterilization. It has been also shown that food colour modulates consumers' motivation to eat [27], therefore, significant colour deviations can have a negative effect on consumer habits and food acceptability.

Based on the results of the puncture test of the whole sample in packaging (Table 7), it can be concluded that processing at $111^{\circ} \mathrm{C}$ is less suitable for borsch and sterilization at $131{ }^{\circ} \mathrm{C}$ is the least suitable for pea soup. However, contrary to the previous data (comparison of preparation methods and 
packaging, Table 4), these results are not that dispersed. With regards to the necessary bite force of product pieces (Table 7), processing at $121^{\circ} \mathrm{C}$ maintained harder beet pieces for borsch, and pea and barley pieces for pea soup compared to other sterilisation temperatures $(p<0.05)$.

Table 7

\section{Hardness of soup fractions at different sterilisation temperatures, $\mathbf{N}$}

\begin{tabular}{|c|c|c|c|c|c|}
\hline \multirow{2}{*}{$\begin{array}{c}\text { Soup } \\
\text { sample }\end{array}$} & \multicolumn{2}{|c|}{ Borsch } & \multicolumn{3}{c|}{ Pea soup } \\
\cline { 2 - 6 } & whole soup & beet pieces & whole soup & pea pieces & barley pieces \\
\hline $\mathrm{D}$ & $3.52 \pm 0.20 \mathrm{a}$ & $0.82 \pm 0.14 \mathrm{a}$ & $13.37 \pm 0.78 \mathrm{a}$ & $0.53 \pm 0.10 \mathrm{a}$ & $1.19 \pm 0.10 \mathrm{a}$ \\
\hline $\mathrm{E}$ & $4.09 \pm 0.28 \mathrm{~b}$ & $0.81 \pm 0.18 \mathrm{a}$ & $13.64 \pm 0.97 \mathrm{a}$ & $0.37 \pm 0.08 \mathrm{~b}$ & $1.07 \pm 0.10 \mathrm{a}$ \\
\hline $\mathrm{F}$ & $3.41 \pm 0.28 \mathrm{a}$ & $1.14 \pm 0.14 \mathrm{~b}$ & $10.67 \pm 0.86 \mathrm{~b}$ & $1.04 \pm 0.12 \mathrm{c}$ & $1.53 \pm 0.15 \mathrm{~b}$ \\
\hline $\mathrm{G}$ & $3.30 \pm 0.25 \mathrm{a}$ & $0.89 \pm 0.19 \mathrm{a}$ & $16.48 \pm 0.87 \mathrm{c}$ & $0.57 \pm 0.09 \mathrm{a}$ & $0.60 \pm 0.14 \mathrm{c}$ \\
\hline
\end{tabular}

Values within the same column sharing the same letter are not significantly different $(p>0.05)$.

Lower and higher processing temperature had a significant influence on the total aroma volatile peak area sums for both soups (Fig. 2). Sterilization at $116^{\circ} \mathrm{C}$ was able to ensure the highest retention of aroma volatiles, which give characteristic aroma notes in borsch; a similar effect was observed for pea soup processed at $116^{\circ} \mathrm{C}$ and $121^{\circ} \mathrm{C}$. Previous research has shown that higher processing temperatures and increased processing time reduce the amount of aroma volatiles in food and it is responsible for significant aroma changes [28-29].

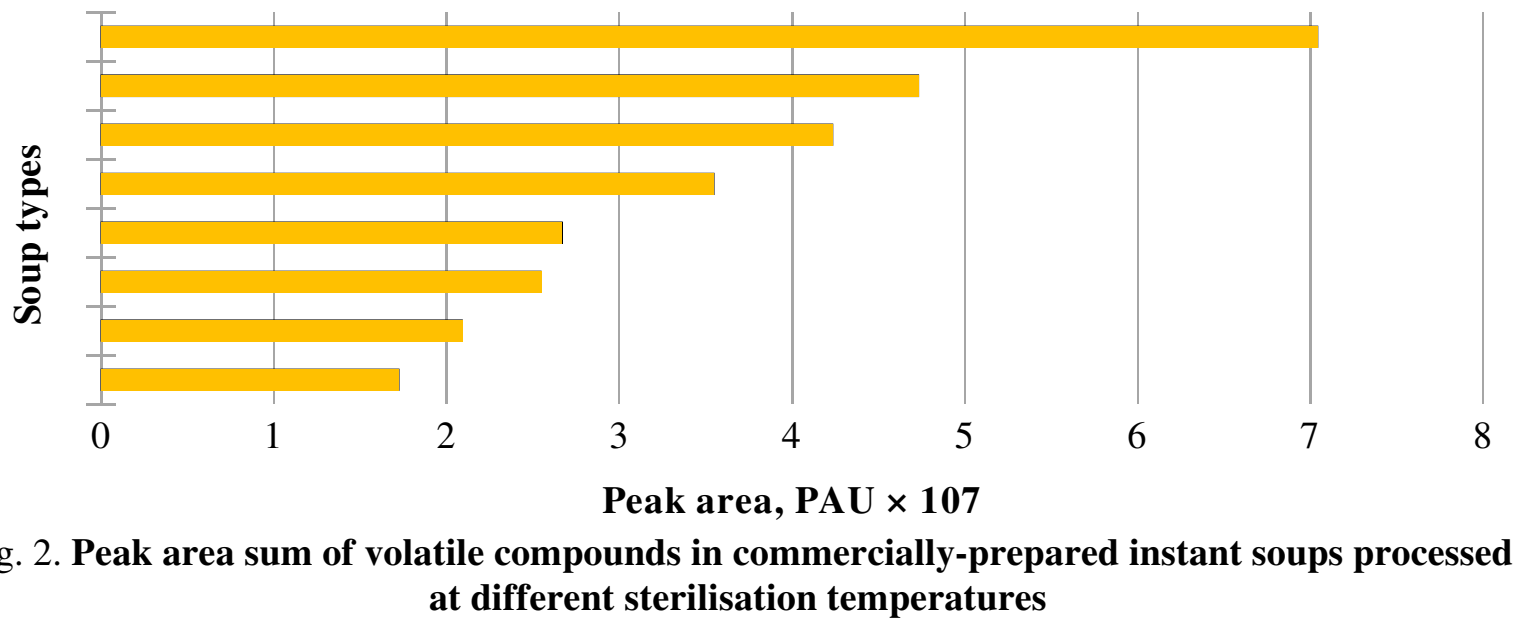

It was possible to successfully identify the most and least suitable sterilization parameters based on sensory evaluation (Table 8). The only acceptable processing treatment in order to obtain very good quality borsch was sterilization at $116^{\circ} \mathrm{C}$ (sample D). Processing at lower and higher temperatures had a detrimental effect and borsch samples were of unsatisfactory quality: experts found non-appetizing broth colour, bitter taste and aftertaste, and overcooked vegetable pieces.

Table 8

\section{Sensory quality of commercially-prepared instant soups at different sterilisation temperatures}

\begin{tabular}{|c|c|c|c|c|}
\hline \multirow{2}{*}{$\begin{array}{c}\text { Soup } \\
\text { sample }\end{array}$} & \multicolumn{2}{|c|}{ Borsch } & \multicolumn{2}{c|}{ Pea soup } \\
\cline { 2 - 5 } & QN & Quality & QN & quality \\
\hline D & 3.0 & very good & 3.0 & very good \\
\hline E & 1.7 & unsatisfactory & 2.4 & average \\
\hline F & 1.6 & unsatisfactory & 2.8 & very good \\
\hline G & 1.3 & unsatisfactory & 1.2 & unsatisfactory \\
\hline
\end{tabular}

There were two temperature regimes $-116^{\circ} \mathrm{C}$ and $121^{\circ} \mathrm{C}$ - suitable to process pea soup (Table 8). Similar to borsch, sterilization at $131^{\circ} \mathrm{C}$ (sample $\mathrm{G}$ ) had an adverse effect on sensory quality of pea soup; it had overcooked pea and potato, the broth was very thick, experts noticed inadequate aroma and unpleasant taste. Sample E (processed at $111^{\circ} \mathrm{C}$ ) was of average quality with such deviations as darker colour and overly tender pea and potato pieces. 
Considering that colour compounds are sensitive to a number of conditions such as $\mathrm{pH}$ variation, oxidation, hydration, heat treatment and, most importantly, exposure to daylight [24], storage conditions have a significant impact on the optimal packaging for both types of soups. As it is very unlikely that glass jars will be kept on grocery store shelves in cardboard boxes (illuminance measured inside a cardboard box gives the value of $0 \mathrm{~lx}$ ), the suggested option at daylight conditions (400$1000 \mathrm{~lx}$ ) is multilayer doypack packaging with aluminium layer, which is able to block over $99 \%$ of light [30], in order to maintain quality during the shelf-life.

\section{Conclusions}

1. The cold preparation method and packaging in doypack is optimal to improve the quality of pea soup.

2. The quality of borsch can be improved using the cold or hot preparation method in doypack, or the cold preparation method in glass jars, however, during long-term storage quality deterioration in glass jars is expected due to daylight exposure.

3. Sterilization at $116^{\circ} \mathrm{C}$ is optimal for borsch as lower and higher temperatures significantly affect its quality, whereas for pea soup two temperature regimes are suitable $-116^{\circ} \mathrm{C}$ and $121{ }^{\circ} \mathrm{C}$.

4. Combination of reduced energy consumption and very good quality of both soup types can be obtained using the cold preparation method and doypack packaging with sterilization at $116^{\circ} \mathrm{C}$ temperature.

\section{Acknowledgements}

The present research leading to these results in accordance with the contract No. 1.2.1.1/16/A/004 between the Latvian Food Competence Centre Ltd. and the Central Finance and Contracting Agency (01.10.2016) has been conducted by Kronis Ltd. with the support from the European Regional Development Fund (ERDF) within the framework of the project Latvian Food Industry Competence Centre.

\section{References}

[1] Olsen N.V., Menichelli E., Sørheim O., Næs T. Likelihood of buying healthy convenience food: An at-home testing procedure for ready-to-heat meals. Food Quality and Preference, vol. 24, iss. 1, 2012, pp. 171-178.

[2] Jackson P., Viehoff V. Reframing convenience food. Appetite, vol. 98, 2016, pp. 1-11.

[3] Featherstone S. Sterilisation systems. In: A Complete Course in Canning and Related Processes: Volume 1: Fundemental Information on Canning Woodhead Publishing Series in Food Science, Technology and Nutrition. Fourteenth Edition. S. Featherstone (ed.). Sawston: Woodhead Publishing, 2015, pp. 239-267.

[4] Peck M.W., van Vliet A.H.M. Impact of Clostridium botulinum genomic diversity on food safety. Current Opinion in Food Science, vol. 10, 2016, pp. 52-59.

[5] Heinz G., Hautzinger P. Meat processing technology for small-to medium-scale producers. Food and Agriculture Organization of the United Nations. [online] [02.10.2018]. Available at: http://www.fao.org/docrep/010/ai407e/AI407E22.htm\#fn11

[6] Zhao H., Cheng N., Zhang Y., Sun Z., Zhou W., Wang Y., Cao W. The effects of different thermal treatments on amino acid contents and chemometric-based identification of overheated honey. LWT - Food Science and Technology, vol. 96, 2018, pp. 133-139.

[7] Knockaert G., De Roeck A., Lemmens L., Van Buggenhout S., Hendrickx M., Van Loey A. Effect of thermal and high-pressure processes on structural and health-related properties of carrots (Daucus carota). Food Chemistry, vol.125, no. 3, 2011, pp. 903-912.

[8] Raval A.H., Solanki S.C., Yadav R. A simplified heat transfer model for predicting temperature change inside food package kept in cold room. Journal of Food Science and Technology, vol. 50, no. 2, 2013, pp.257-265.

[9] Ito R., Fukuoka M., Hamada-Sato N. Innovative food processing technology using ohmic heating and aseptic packaging for meat. Meat Science, vol. 96, 2014, pp. 675-681.

[10] Awuah G.B., Ramaswamy H.S., Economides A. Thermal processing and quality: Principles and overview. Chemical Engineering and Processing: Process Intensification, vol. 46, issue 6, 2007, pp. 584-602. 
[11]Barbosa-Cánovas G.V., Medina-Meza I., Candoğan K., Bermúdez-Aguirre D. Advanced retorting, microwave assisted thermal sterilization (MATS), and pressure assisted thermal sterilization (PATS) to process meat products. Meat Science, vol. 98, iss. 3, 2014, pp. 420-434.

[12] Habekost M. Which color differencing equation should be used? International Circular of Graphic Education and Research, no. 6, 2013, pp. 20-33.

[13] Cserhalmi Z., Sass-Kiss A., Tóth-Markus M., Lechner N. S. Study of pulsed electric field treated citrus juices. Innovative Food Science \& Emerging Technologies, vol. 7, no. 1-2, 2006, pp. 49-54.

[14] Andrés V., Villanueva M. J., Tenorio M. D. The effect of high-pressure processing on colour, bioactive compounds, and antioxidant activity in smoothies during refrigerated storage. Food Chemistry, vol. 192, 2016, pp. 328-335.

[15]Fernández-Vázquez R., Stinco C.M., Hernanz D., Heredia F.J., Vicario I.M. Colour training and colour differences thresholds in orange juice. Food Quality and Preference, vol. 30, 2013, pp. 320-327.

[16] Straumite E., Kruma Z., Galoburda R., Saulite K. Effect of blanching on the quality of microwave vacuum dried dill (Anethumgraveolens L.). International Journal of Biological, Biomolecular, Agricultural, Food and Biotechnological Engineering, vol. 64, 2012, pp. 756-762.

[17]Featherstone S. Retortable flexible containers for food packaging. In: A Complete Course in Canning and Related Processes: Volume 2: Microbiology, Packaging, HACCP and Ingredients. Fourteenth Edition. S. Featherstone (ed.). Sawston: Woodhead Publishing, 2015, pp. 137-146.

[18] Brockgreitens J., Abbas A. Responsive Food Packaging: Recent Progress and Technological Prospects. Comprehensive Reviews in Food Science and Food Safety, vol. 15, no. 1, 2016 pp. 315.

[19] Cafieria S., Chilloa S., Mastromatteo M., Suriano N., Del Nobile M.A. A mathematical model to predict the effect of shape on pasta hydration kinetic during cooking and overcooking. Journal of Cereal Science, vol. 48, iss. 3, 2008, pp. 857-862.

[20] Odor description. The Good Scents Company Information System Providing information for the Flavor, Fragrance, Food and Cosmetic industries. [online] [02.10.2018]. Available at: http://www.thegoodscentscompany.com/index.html

[21] Honkanen P., Frewer L. Russian consumers' motives for food choice. Appetite, vol. 52, 2009, pp. 363-371.

[22] Shah M.A., Don Bosco S.J., Mir S.A., ValiyapeediyekkalSunooj K. Evaluation of shelf life of retort pouch packaged Rogan josh, a traditional meat curry of Kashmir, India. Food Packaging and Shelf Life, vol. 12, 2017, pp. 76-82.

[23] SadilSadilova E., Stintzing F.C., Kammerer D.R., Carle R. Matrix dependent impact of sugar and ascorbic acid addition on color and anthocyanin stability of black carrot, elderberry and strawberry single strength and from concentrate juices upon thermal treatment. Food Research International, vol. 42, 2009, pp. 1023-1033.

[24] Ghidouche S., Rey B., Michel M., Galaffu N. A rapid tool for the stability assessment of natural food colours. Food Chemistry, vol. 139, 2013, pp. 1-4.

[25]Dutta D., Dutta A., Raychaudhuri U., Chakraborty R. Rheological characteristics and thermal degradation kinetics of beta-carotene in pumpkin puree. Journal of Food Engineering, vol. 76, no. 4, 2006, pp. 538-546.

[26]Zepka L.Q., Borsarelli C.D., da Silva M.A.A.P., Mercadante A.Z. Thermal degradation kinetics of carotenoids in a cashew apple juice model and its impact on the system color. Journal of Agricultural and Food Chemistry, vol. 57, 2009, pp. 7841-7845.

[27] Suzuki M., Kimura R., Kido Y., Inoue T., Moritani T., Nagai N. Color of hot soup modulates postprandial satiety, thermal sensation, and body temperature in young women. Appetite, vol. 114, 2017, pp. 209-216.

[28] Wang Y., Li W., Ma Y., Zhao X., Zhang C. Effect of Thermal Treatments on Quality and Aroma of Watermelon Juice. Journal of Food Quality, vol. 2018, 2018, 7 pages.

[29] Sabovics M., Straumite E., Galoburda R. The influence of baking temperature on the quality of triticale bread. Conference Proceedings of 9 th Baltic Conference on Food Science and Technology „Food for Consumer Well - Being” FOODBALT 2014, May 8-9, 2014, Jelgava, Latvia, pp. 228-233.

[30] Papadakis S.E. (2016) Food Packaging and Aseptic Packaging. In: Handbook of Food Processing: Food Preservation. T. Varzakas, C. Tzia (eds.). Boca Raton: CRC Press, 2016, pp. 571-649. 